\title{
ESTIMATING TOTAL GLOMERULAR NUMBER IN HUMAN KIDNEYS WITH A PHYSICAL DISECTOR/FRACTIONATOR COMBINATION
}

\author{
KELli J JOHNSON ${ }^{1}$, NigEL G WREFORD ${ }^{1}$, WENDY E HOY ${ }^{2}$ AND JOHN F BERTRAM ${ }^{1}$ \\ ${ }^{1}$ Department of Anatomy, Monash University, Clayton, Victoria, 3800; ${ }^{2}$ Menzies School of Health Research, \\ Casuarina, Darwin, Northern Territory, 0810, Australia \\ (Accepted April 19, 2000)
}

\begin{abstract}
End-stage renal disease (ESRD) has emerged as a major health issue for Australian Aborigines. This phenomenon is paralleled in other populations that have adopted a Westernised lifestyle, including African Americans. It has been suggested that abnormal glomerular hypertrophy (glomerulomegaly) is an important predisposing factor for ESRD. The pathogenesis of glomerulomegaly remains unknown. It may represent a compensatory hypertrophic response to decreased nephron endowment during fetal development. Alternatively, glomerulomegaly may represent an abnormal haemodynamic/metabolic response to repeated infections, including renal infections during postnatal life. Since glomerular number and size are important issues associated with ESRD, an optimum quantitative method is required for estimating these parameters in human kidneys. The total number of glomeruli in the normal human kidney appears to vary by a factor of three or more, ranging from approximately 300,000 to more than 1 million. Recently, unbiased stereological methods for estimating total glomerular number in kidneys have been developed. The general aim of the present study was to evaluate (in terms of precision and efficiency) a stereological method for estimating total glomerular number in human kidneys; the physical disector/fractionator combination. This method provided consistent estimates of total glomerular number. Estimates of total glomerular number obtained for four human kidneys ranged from 364,161 to 586,094 (coefficients of variation $9.2 \%$ to $20.0 \%$ ). Mean

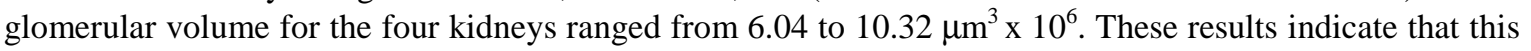
method is a precise and consistent method for estimating total glomerular number in human kidneys. The simple sampling technique developed in this study will be employed in future studies to determine if there is a difference in total glomerular, and hence nephron, number between Australian Aborigines and Caucasians, and between African and Caucasian Americans.
\end{abstract}

Keywords: fractionator, glomerular number, kidney, physical disector.

\section{INTRODUCTION}

ESRD is a major health problem for Australian Aborigines, with the incidence being approximately 20 times greater than in non-Aborigines. This rate is expected to increase a further 2.5 - fold by the year 2000 (Hoy et al., 1998). A similar phenomenon is being witnessed in other populations that have adopted a Westernised lifestyle including African Americans whose rate of ESRD is approximately 4-fold higher than in Caucasian Americans (Klag et al., 1997). Glomerulomegaly is more common in renal biopsies of Australian Aborigines than in non-Aborigines (Bertram et al., 1998; Kirubakaran 1998). The pathogenesis of glomerulomegaly remains unknown. It has been suggested that it is a compensatory hypertrophic response secondary to reduced nephron endowment during fetal development. It has also been suggested that glomerulomegaly may represent a response to abnormal haemodynamic or metabolic factors and/or repeated renal infections in postnatal life.

Since glomerular number and size are important issues associated with ESRD, an optimum quantitative method is required for estimating these parameters in human kidneys. The present study was designed to evaluate and optimize a variant of the physical disector/fractionator stereological combination (Nyengaard and Bendtsen, 1992).

\section{MATERIALS AND METHODS}

\section{SPECIMENS}

Four human kidney samples were obtained from the Forensic Pathology Unit at Territory Health Services, Royal Darwin Hospital, Casuarina, Northern Territory, Australia. Ethics approval was obtained 
from the Joint Institutional Ethics Committee of the Royal Darwin Hospital, Casuarina, NT, Australia and the Menzies School of Health Research, Darwin, NT, Australia. The following steps were performed at autopsy. (1) The right kidneys were removed from cadavers and trimmed of any fat. The renal artery was left intact for perfusion. The kidney was weighed (fresh weight). A cannula was tied into the renal artery and the kidney perfused with $10 \%$ formalin for approximately $5 \mathrm{~min}$. The renal artery was cut away with any fat at the hilar region and the kidney weighed again (fixed weight). (2) The kidneys were cut along the frontal plane into two halves (approximately), and one "half" was chosen randomly for further analysis. The other "half" was placed back into the cadaver. (3) The sampled "half" was sliced into $4 \mathrm{~mm}$ slices using a razor blade slicing device perpendicular to the first sampling stage and immersion-fixed in $10 \%$ buffered formalin. Every $4^{\text {th }}$ slice was taken for further analysis with the first slice being chosen in the interval 1-4. Approximately 5 slices were sampled for each kidney. These sampled slices were weighed. The non-sampled slices were also placed back into the cadaver as required by the ethics committee.

\section{FURTHER SAMPLING}

Every $4^{\text {th }}$ kidney slice was cut into $5 \mathrm{~mm}$ strips. The strips were cut into smaller blocks of tissue so that they were all approximately the same size. At this point the pieces of tissue were at block size and no further sampling was necessary. Because there was still some variation in block size they were arranged from smallest to largest prior to the next sampling stage. In order to obtain approximately 1520 blocks, every $25^{\text {th }}$ block of tissue was sampled. The tissue blocks were subjected to further immersion-fixation in $10 \%$ buffered formalin for approximately 2 days, and then placed into $70 \%$ ethanol for 1-2 days prior to processing. Blocks were then processed for embedding in glycolmethacrylate (Technovit 7100, Heraeus Kulzer Gmbh, Germany). Blocks were exhaustively sectioned at a nominal thickness of $20 \mu \mathrm{m}$ using a Leica DM2165 Supercut rotary microtome with every $10^{\text {th }}$ and $11^{\text {th }}$ sections sampled and stained with haematoxylin and eosin.

\section{ESTIMATING TOTAL GLOMERULAR NUMBER $\left(\mathrm{N}_{\text {glom, kid }}\right)$}

Every $10^{\text {th }}$ section was viewed on a Fuji Minicopy Reader at a magnification of $24.25 x$. An orthogonal grid $(4 \mathrm{~cm} \times 4 \mathrm{~cm})$ was placed on the viewing screen. Points hitting tissue were counted $\left(\mathrm{P}_{\mathrm{S}}\right)$. Those sections with an intact face of the tissue block were circumscribed and used for glomerular counting. Sections not circumscribed had been cut too close to artificial surfaces and were excluded from glomerular counting. The circumscribed sections (with their pair) were projected at a magnification of 60x using Olympus $\mathrm{BH}-2$ light microscopes modified for projection. An orthogonal grid $(4 \mathrm{~cm} \times 4 \mathrm{~cm})$ was superimposed over the visual field of the sampled sections. Crosses within the grid were used to estimate $\mathrm{P}_{\mathrm{F}}$, or the area of tissue allowed for counting glomeruli (Nyengaard and Bendtsen 1990; Nyengaard and Bendtsen, 1992). Glomeruli were counted using physical disectors (Nyengaard and Bendtsen, 1990). A glomerulus was counted if (a) it was sampled in the unbiased counting frame of the sampled section and did not touch the 'forbidden line'; (b) if there were no artificial edges of the section within the frame or its guard area; and (c) it was not present in the 'look-up' section. The unbiased counting frame was the same size as one grid square with a guard area in adjacent squares. In order to double the counting efficiency, glomeruli were counted in both directions. ie. The look-up section was now used as the sampled section.

Total glomerular number was estimated using:

$$
\mathrm{N}_{\text {glom, kid }}=\mathrm{f}_{1} \times 25 \times 10 \times\left(\mathrm{P}_{\mathrm{S}} / 2 \mathrm{P}_{\mathrm{F}}\right) \times \mathrm{Q}^{-}
$$

where $f_{1}$ is the reciprocal of the first stage sampling fraction defined as the weight of the sampled slices divided by the weight of the whole kidney, 25 was the inverse of the second sampling fraction $(1 / 25$ of the blocks), 10 was the inverse of the section sampling fraction (1/10 of the sections), $\mathrm{P}_{\mathrm{S}} / 2 \mathrm{P}_{\mathrm{F}}$ was the fraction of the section area used for glomerular counting, and $\mathrm{Q}^{-}$was the actual number of glomeruli counted. Approximately 150-200 glomeruli were counted for each kidney.

Grid points overlying glomerular tufts $\left(\mathrm{P}_{\text {glom }}\right)$ and renal corpuscles $\left(\mathrm{P}_{\text {corp }}\right)$ were also counted. Mean glomerular tuft $\left(\mathrm{V}_{\text {glom }}\right)$ and mean renal corpuscle $\left(\mathrm{V}_{\text {corp }}\right)$ volumes were estimated using:

$$
\begin{gathered}
\mathrm{V}_{\text {glom }}=\mathrm{V}_{\mathrm{V} \text { (glom,kid) }} / \mathrm{N}_{\mathrm{V}(\text { glom,kid) }} \text {, and } \\
\mathrm{V}_{\text {corp }}=\mathrm{V}_{\mathrm{V} \text { (corp,kid) }} / \mathrm{N}_{\mathrm{V} \text { (corp,kid) }}
\end{gathered}
$$

\section{STATISTICS}

Values are expressed as mean \pm standard deviation.

\section{RESULTS}

Total glomerular number was estimated in three samples of blocks for all four kidneys. These 
estimates are shown in Table 1. For three of the four kidneys, the agreement between the triplicate estimates was excellent, with coefficients of variation (CV) of $9.2 \%$ to $12.5 \%$. For kidney 2, the agreement between the three estimates was not as good, with a $\mathrm{CV}$ of $20.0 \%$. The mean estimates of total glomerular number ranged from 364,161 in Kidney 4 to 586,094 in Kidney 3.

Estimates of mean glomerular volume are also shown in Table 1. Estimates for the four kidneys ranged from 6.04 to $10.32 \mu^{3} \times 10^{6}$. Mean glomerular volume for the four kidneys was $8.04 \mu \mathrm{m}^{3} \times 10^{6}$.

\section{DISCUSSION}

The major findings from the present study were: (1) the physical disector/ fractionator combination provided reproducible estimates of total glomerular number; and (2) mean glomerular number in four human kidneys was 510,001, ranging from 364,161 to 586,094 .

The major difference between the present method for counting glomeruli and the method of Nyengaard and Bendsten (1992) is that we have used weights of tissue pieces at the first two sampling levels rather than relying entirely on number fractions, and have cut the tissue blocks to be approximately the same size. In the present study, we found that the first two sampling steps (cutting the kidney in "half" and sampling every fourth slice from one "half") did not always provide a sample close to $12.5 \%$ of the weight of the kidney. We therefore adopted the use of a weight fraction to determine the fraction of the kidney obtained at autopsy, although the use of weights may introduce a small bias. Moreover, the strips obtained also differed greatly in size. We therefore decided to cut all of the strips into blocks of approximately equal size. The sampling was further modified by analysing the blocks from smallest to largest prior to sampling. We then sampled $1 / 25^{\text {th }}$ of these blocks. These strategies, we believe, have enabled us to obtain a precise fractionation of the kidney. This is evident by the low CV's obtained for the triplicate measurements in three of the four kidneys. The data obtained for Kidney 2 is more variable, and possibly reflects the fact that one of the samples contained more blocks than the other two samples.

The present findings indicate that the physical disector/fractionator is a consistent method for estimating glomerular number and size in human kidneys, and this is the method we will employ in our studies on Australian Aborigines and African Americans, and control Caucasian populations.

Table 1: Stereological estimates for four human kidneys.

\begin{tabular}{lllll}
\hline Estimates & Kidney & Kidney & Kidney & Kidney \\
& 1 & 2 & 3 & 4 \\
\hline Total glomerular number & & & & \\
Estimate 1 & 550,373 & 508,236 & 525,521 & 336,571 \\
Estimate 2 & 546,270 & 510,561 & 628,836 & 407,548 \\
Estimate 3 & 437,798 & 716,020 & 603,925 & 348,364 \\
& & & & \\
Mean & 511,480 & 578,272 & 586,094 & 364,161 \\
SD & 63,844 & 119,299 & 53,916 & 38,034 \\
CV $(\%)$ & 12.5 & 20.7 & 9.2 & 10.4 \\
& & & & \\
Mean glomerular volume & & & & \\
$\left(\mu m^{3} \times 10^{6}\right)$ & & & 9.90 & 11.90 \\
Estimate 1 & 6.93 & 4.34 & 7.36 & 8.73 \\
Estimate 2 & 6.51 & 5.81 & 7.34 & 10.34 \\
Estimate 3 & 9.33 & & & \\
& & 6.04 & 8.21 & 10.32 \\
Mean & 7.59 & 1.21 & 1.47 & 1.59 \\
SD & 1.52 & 20.0 & 17.9 & \\
CV $(\%)$ & 20.0 & & & \\
\hline
\end{tabular}


A preliminary report of some of the data was presented at the $\mathrm{X}^{\text {th }}$ International Congress for Stereology, Melbourne, Australia, 1-4 November 1999.

\section{ACKNOWLEDGMENT}

This research was supported by the National Health and Medical Research Council of Australia, and Janssen-Cilag Pty. Ltd.

\section{REFERENCES}

Bertram JF, Soosaipillai MC, Ricardo SD, Ryan GB (1992). Total numbers of glomeruli and individual glomerular cell types in the normal rat kidney. Cell Tissue Res 270:37-45.

Bertram JF (1995). Analyzing renal glomeruli with the new stereology. Int Rev Cytol 161:111-72.

Bertram JF, Young RJ, Seymour AE, Kincaid-Smith P, Hoy W (1998). Glomerulomegaly in Australian Aborigines. Nephrology 4:S46-S53.
Gundersen HJG, Østerby R (1977). Glomerular size and structure in diabetes mellitus. II. Late abnormalities. Diabetologia 13:43-8.

Hoy WE, Mathews JD, Wang Z, McCredie DA, Hayhurst BG, Pugsley DJ, Norman RJ, McFarlane R, Rees M, Kile E, Walker K (1998). Towards an epidemiologic definition of renal disease: Rates and associations of albuminuria in a high-risk Australian Aboriginal community. Nephrology 4:S59-S65.

Kirubakaran MG (1998). The Central Australian Aboriginal Renal Disease Registry. Nephrology 4:S83-S85.

Klag MJ, Whelton PK, Randall BL, Neaton JD, Brancati FL, Stamler J (1997). End-stage renal disease in African-American and white men. 16-year MRFIT findings. JAMA 277(16):1293-8.

Nyengaard JR, Bendtsen TF (1990). A practical method to count the number of glomeruli in the kidney as exemplified in various animal species. Acta Stereol 9(2):243-58.

Nyengaard JR, Bendtsen TF (1992). Glomerular number and size in relation to age, kidney weight, and body surface in normal man. Anat Rec 232(2):194-201. 